\title{
Ecogeographical Variation in Skull Shape of South-American Canids: Abiotic or Biotic Processes?
}

\author{
Jamile de Moura Bubadué ${ }^{1}$ Nilton Cáceres ${ }^{2} \cdot$ Renan dos Santos Carvalho $^{2}$. \\ Carlo Meloro ${ }^{3}$
}

Received: 2 July 2015/Accepted: 31 October 2015/Published online: 7 December 2015

(c) The Author(s) 2015. This article is published with open access at Springerlink.com

\begin{abstract}
Species morphological changes can be mutually influenced by environmental or biotic factors, such as competition. South American canids represent a quite recent radiation of taxa that evolved forms very disparate in phenotype, ecology and behaviour. Today, in the central part of South America there is one dominant large species (the maned wolf, Chrysocyon brachyurus) that directly influence sympatric smaller taxa via interspecific killing. Further south, three species of similar sized foxes (Lycalopex spp.) share the same habitats. Such unique combination of taxa and geographic distribution makes South American dogs an ideal group to test for the simultaneous impact of climate and competition on phenotypic variation. Using geometric morphometrics, we quantified skull size and shape of 431 specimens belonging to the eight extant South American canid species: Atelocynus microtis, Cerdocyon thous, Ch. brachyurus, Lycalopex culpaeus, L. griseus, L. gymnocercus, $L$. vetulus and Speothos venaticus. South American canids are significantly different in both
\end{abstract}

Electronic supplementary material The online version of this article (doi:10.1007/s11692-015-9362-3) contains supplementary material, which is available to authorized users.

Carlo Meloro

C.Meloro@ljmu.ac.uk

1 Programa de Pós-Graduação em Biodiversidade Animal, CCNE, Federal University of Santa Maria, Santa Maria, RS 97110-970, Brazil

2 Department of Ecology and Evolution, CCNE, Federal University of Santa Maria, Santa Maria, RS 97110-970, Brazil

3 Research Centre in Evolutionary Anthropology and Palaeoecology, School of Natural Sciences and Psychology, Liverpool John Moores University, Byrom Street, Liverpool L3 3AF, UK skull size and shape. The hypercarnivorous bush dog is mostly distinct in shape from all the other taxa while a degree of overlap in shape-but not size - occurs between species of the genus Lycalopex. Both climate and competition impacts interspecific morphological variation. We identified climatic adaptations as the main driving force of diversification for the South American canids. Competition has a lower degree of impact on their skull morphology although it might have played a role in the past, when canid community was richer in morphotypes.

Keywords Canidae - Carnivora - Climatic adaptations . Geographic clines · Interspecific competition ·

Macroecology

\section{Introduction}

Understanding species community assembly is one of the central aims of macroecology (Rosenzweig 1995). For instance, on the one side, we expect abiotic forces, such as climate and geographical barriers, to apply filters influencing species distribution and community composition. On the other side, biotic competition might produce unexpectedly stable species assemblages. Such balancing forces are clearly not mutually exclusive and we have strong evidence that the majority of animal groups tend to be quite resilient and less sensitive to abiotic forces than expected by theory (Vrba 1993). In this regards, members of the mammalian order Carnivora received particular attention for being endothermic, ecologically diverse and secondary consumers (Goswami 2010). The red fox (Vulpes vulpes), for instance, is the commonest species to provide evidence for the impact of climate on phenotypes, particularly in skull size, which varies with latitude 
(Churcher 1960; Davis 1977; Cavallini 1995; Yom-Tov and Geffen 2006; Meiri et al. 2007; Yom-Tov et al. 2007; Szuma 2008). Other lines of investigations on carnivorans' skull took direct competition into account for explaining carnivoran assembly rules (Dayan et al. 1989, 1992; Dayan and Simberloff 2005; Meiri et al. 2011).

Carnivora generally exhibit broad range of ecological and phenotypic variation accompanied by behavioural attributes (e.g. predatory/killing behaviour) that makes them particularly sensible to biotic processes (Palomares and Caro 1999; Donadio and Buskirk 2006). Here, we use South-American canids as model species to test the hypothesis that climate and competition might have a direct impact on species morphological variation at broad geographical scale. South-American canids represent a recent radiation due to their late Pliocene colonization from a restricted pool of North American taxa (Berta 1987; Prevosti 2010; Perini et al. 2010; Wang et al. 2008). Despite this, South America holds more than 10 living canid species, being the largest extant regional diversity found in the world (Prevosti et al. 2009a; Perini et al. 2010; SilleroZubiri et al. 2004). Its endemic taxa includes species with a broad diversity of body size and feeding ecology such as the large (average mass $=25 \mathrm{~kg}$ ) omnivorous maned wolf Chrysocyon brachyurus (Illiger, 1815) and the small (mass ranging $5-8 \mathrm{~kg}$ ) hypercarnivorous bush dog Speothos venaticus (Lund, 1842) (Sillero-Zubiri et al. 2004).

Diversity of fox-like ecomorphs is also broad including species such as the widely distributed crab-eating fox (Cerdocyon thous) and the four species of Lycalopex that share to some extent geographic range, especially in Argentina, and omnivorous feeding habits. Such a high diversity was even higher during the prehistory (Prevosti 2010; Perini et al. 2010) with larger carnivorous wolflike forms possibly influencing ecology and distribution of smaller taxa.

Currently, we have direct evidence on the impact of competition on ecology and behaviour of extant SouthAmerican canids. Di Bitetti et al. (2009) recorded patterns of behavioural shift by Lycalopex gymnocercus due to competition with $C$. thous. In sympatry, L. gymnocercus changes its normal activity to prevent confrontation with the larger $C$. thous. Also, interspecific killing occurs quite intensively, with large taxa, such as Ch. brachyurus, generally controlling densities and behaviour of smaller species (Donadio and Buskirk 2006; Oliveira and Pereira 2014).

Skulls of South-American wild dogs received reasonable attention to clarify patterns of growth and taxonomy (Segura and Prevosti 2012; Segura 2013), paleobiological and ecological adaptations (Prevosti et al. 2005; Prevosti et al. 2009a, b), and more recently climatic impact (Machado and Hingst-Zaher 2009; Martinez et al. 2013), but little is known about the impact of competition on their intra and interspecific variation. Wayne et al. (1989) identified high degree of morphological divergence between South-American foxes in spite of their relatively short time of divergence $(<250,000$ years) and we might expect this to occur even strongly when larger taxa are included.

By focusing our investigation on both climate and competition, we aim to provide a fully comprehensive framework to interpret skull morphology of the extant South-American canids at broad, continental scale. We opted to quantify skull size and shape by using geometric morphometrics as a good proxy for phenotypic variation at broad geographical scale (see also Cáceres et al. 2014; Meloro et al. 2014a, b). This method was favoured among others because it allows direct and independent visualizations of size and shape patterns together with higher statistical power with reasonably large sample sizes (Adams et al. 2004, 2013).

More specifically our aim is to test the following hypotheses:

1. South American canids differ in both skull size and shape;

2. Size influences shape differences between species;

3. Skull shape and size co-vary with climatic variables and degree of competition across species;

4. Species follow distinct phenotypic patterns of skull shape changes in relation to broad environmental variables or to different degrees of competition.

Hypothesis 1 concerns the biological paradigm of interspecific differentiation and functional convergence. Functional convergence in the skull of carnivorans has been very often detected in relation to extreme feeding adaptations (e.g. durophagy, Figueirido et al. 2011, 2013 or solitary hunting, Meloro et al. 2015a). Meloro (2011), Meloro and Raia (2010) and Meloro and O’Higgins (2011) identified morphological similarities also between omnivores (i.e., canids and viverrids) and we might expect some overlap between South-American taxa with similar diet. Hypothesis 2 relates to the recent findings by Cáceres et al. (2014) and Meloro et al. (2014a, b) on geographical variation of capuchin and howler monkeys: in these cases a significant allometric component was detected also across geographic localities so that skull shape differences were mostly influenced by size.

Hypotheses 3 and 4 relate to ecogeographical pattern generally identifiable in the mammalian skull (Cardini et al. 2007). If abiotic forces are more relevant to regulate canid community assembly we might expect stronger covariation between skull morphology and climate then between skull morphology and competition. The opposite might occur if biotic forces are more relevant. 


\section{Materials and Methods}

\section{Raw Data and Geometric Morphometrics}

Our sample includes skull pictures in ventral view of 431 wild-caught adult canid specimens of South America (Online Resource). For each specimen we recorded the geographic coordinates of its collection locality resulting in 262 different localities covering seven countries (Fig. 1; see also Table 1).

Skull pictures were taken at fixed distance $(2 \mathrm{~m})$. This procedure standardizes the sample of digital images and minimizes deformation due to the lenses (as in Meloro et al. 2008). When taking pictures, we set up a scale bar adjacent to the specimen in order to transform digital pixels in linear measurements (Zelditch et al. 2004).

Ventral view was chosen because the palate of canids is relatively flat and the teeth can be individually recognized. Digital photographs were landmarked by one of us (JMB) using the tpsDig2 ver. 2.16 (Rohlf 2015). Landmarking by only one investigator allowed to minimize inter-observer error and repeated sessions on 10 random specimens were taken to assess landmark repeatability
Fig. 1 Map of South America showing the geographic distribution of canid skull specimens. Sampling localities of different species are shown by different symbols

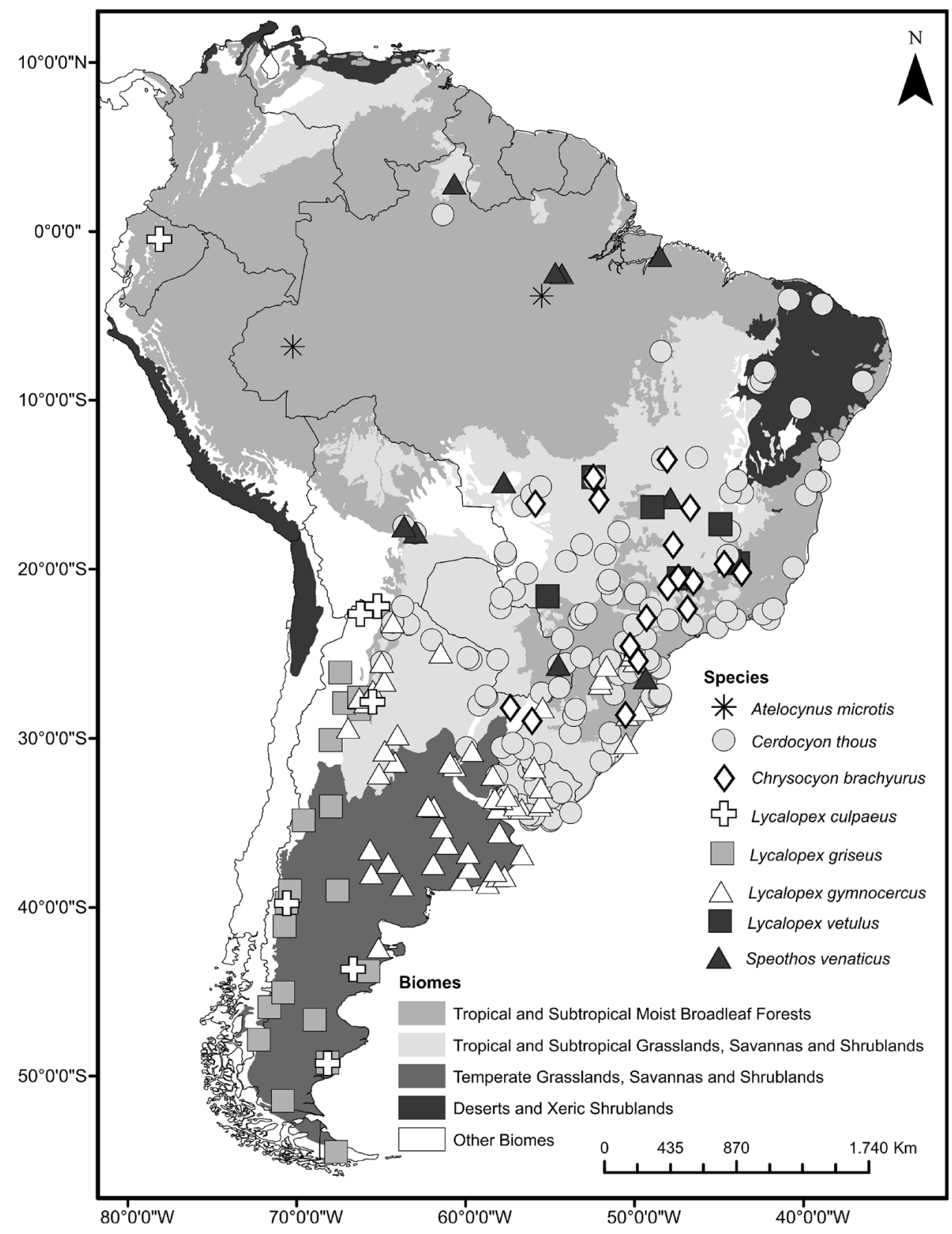


Table 1 Skull sample size for the eight species of canids included in this study

\begin{tabular}{lccrc}
\hline Species & \# Specimens & \# Females & \# Males & Undet \\
\hline Atelocynus microtis (Sclater, 1882) & 4 & 1 & 3 & 0 \\
Cerdocyon thous (Linnaeus, 1766) & 227 & 71 & 94 & 62 \\
Chrysocyon brachyurus (Illiger, 1815) & 25 & 5 & 7 & 13 \\
Lycalopex culpaeus (Molina, 1782) & 13 & 5 & 4 & 4 \\
Lycalopex griseus (Gray, 1837) & 32 & 9 & 4 & 19 \\
Lycalopex gymnocercus (Fischer, 1814) & 99 & 38 & 28 & 33 \\
Lycalopex vetulus (Lund, 1842) & 16 & 7 & 5 & 4 \\
Speothos venaticus (Lund, 1842) & 15 & 3 & 10 & 2 \\
Total & 431 & 139 & 155 & 137 \\
\hline
\end{tabular}

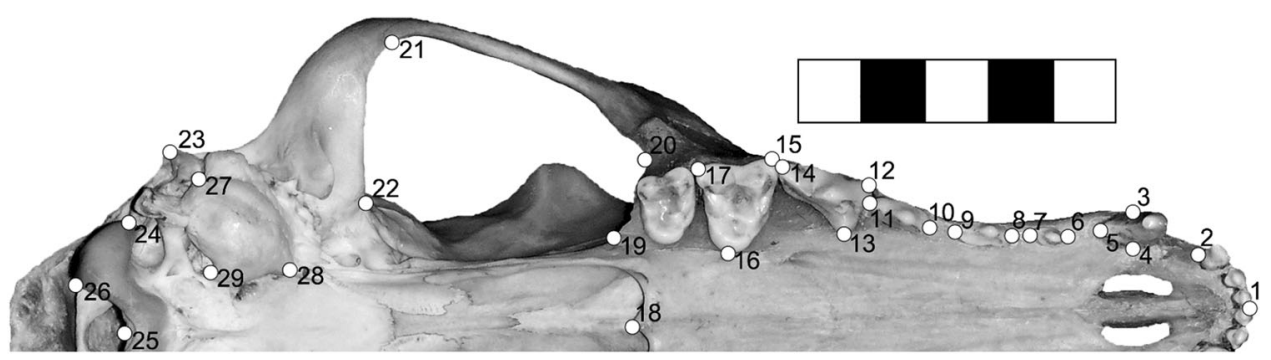

Fig. 2 Disposition of 29 landmarks on a skull of Chrysocyon brachyurus specimen. 1 Midpoint of central incisors; 2 posteriormost point of lateral incisor alveolus; 3-5 canine area; 6-7 first premolar length; 8-9 second pre-molar length; 10-11 third pre-molar

(Cardini and Tongiorgi 2003; Meloro 2011; Meloro et al. 2014a)

In order to describe effectively craniodental morphology, we digitized 29 homologous landmarks (Fig. 2). The landmarks recorded the overall skull shape, zygomatic arch, rostrum (palate), auditory bulla, and position and size of the teeth, being all features generally related to feeding adaptations in Carnivora and Canidae (Schutz et al. 2009; Segura and Prevosti 2012; Meloro et al. 2015b).

Generalized procrustes analysis (GPA, Rohlf and Slice 1990) allowed us to remove from the original landmark coordinates differences in size, position and orientation. This procedure transforms raw landmarks coordinates into shape variables: the procrustes coordinates. The GPA coordinates were projected into a weight matrix to characterize shape using non-affine (Partial Warps) and affine (uniform) components of thin plate spline. A principal component analysis of the weight matrix (=relative warp analysis, RWA) allowed us to visualize shape changes of each specimen relative to the mean shape (Zelditch et al. 2004). Skull size was directly extrapolated from raw landmark coordinates using the centroid size (Rohlf 2000). We used the software tpsRelw version 1.49 (Rohlf 2015) to compute GPA, extract the weight matrix, and to compute a RWA. length; 12-14 fourth pre-molar (carnassial) area; 15-17 first molar area; 18 most posterior tip of the palatine; $19-22$ zygomatic arch area; 23 tip of paracondylar process; 24-26 occipital condyle area; 27-29 auditory bulla area

\section{Statistical Analyses}

\section{Taxonomy and Sexual Dimorphism}

To prevent pseudoreplication and have better estimation of shape and size in each locality, we used the average values of our geometric morphometric results per locality and sex in all statistical analyses (Cardini et al. 2007; Cáceres et al. 2014).

We used ANOVA and MANOVA to test if canid species, used as factor named "taxonomy", differ in skull size and shape. Sex was also included as factor in the models where taxonomy and sex were tested for interaction (Cardini and Elton 2008). Scores of a selection of Relative Warp axes that explained at least $95 \%$ of variance were included as dependent variables in the MANOVA models to reduce degrees of freedom in relation to sample size of particularly small groups (Meloro and O'Higgins 2011).

\section{Allometry}

In order to quantify the allometric effects on our sample, we used the natural $\log$ transformed centroid size $(=\operatorname{lnCS})$ in all the analyses as an independent variable. The strength of allometric signal was tested separately in the whole $(\mathrm{N}=461)$ and in the locality averaged sample $(\mathrm{N}=262)$ 
of skulls using MorphoJ (Klingenberg 2011) by performing a multivariate regression of $\operatorname{lnCS}$ on skull shape (cf. Cáceres et al. 2014; Meloro et al. 2014a, b). Together with global allometry (that assumes no difference in slope occurs between species subgroups) we also tested for allometry using pooled regression within subgroups (Klingenberg 1996). Using the $\mathrm{R}$ environment, version 2.8.1 (R Development Core Team 2013) and the package geomorph (Adams and Otarola-Castillo 2013) we tested for differences in allometric slope between species by running an ANOVA model with interaction using shape (as procrustes distances) as dependent variable, ln CS as covariate and species as factor. We run 9999 permutations to validate reliability of the $P$ value. Additionally, the global and locality averaged skull sample were subdivided into single species dataset in order to identify the strength of allometry in different taxa and link these results to taxon-specific variation partitioning models (see below).

\section{Ecogeographical Variation}

To test for the impact of geography on skull shape we employed each specimen collection locality to extract nineteen bioclimatic variables with a resolution of $10^{\prime}$ from the WorldClim raster database (Hijmans et al. 2005) by using the DIVA-GIS 7.5 software (http://www.diva-gis.org/download).

Two block partial least squares (=PLS; Rohlf and Corti 2000) was applied using tpsPLS v.1.18 (Rohlf 2015) to test the relationship between climate and skull shape. PLS extracts vectors from the correlation matrix of each block so that the degree of co-variation between one block and the other is maximized (Rohlf and Corti 2000). In MorphoJ (Klingenberg 2011) we also employed PLS to test the correlation between size (lnCS) and the 19 bioclimatic variables. Although this procedure generates only one pair of vectors, it allows performing comparisons with PLS vectors obtained for shape (see Meloro and Jones 2012).

\section{Competition}

To identify the possible impact of competition on skull shape and size we ascribed to each geographic locality the presence/absence of distinct canid species that were characterized according to their diet, body mass, and biome preference (Sillero-Zubiri et al. 2004).

For each focal species recorded at a certain locality we recorded the number of canid taxa that could potentially interact with it due to dietary adaptation, habitat preference and body size. For each locality we recorded the number of canids with the same diet and habitat and standardized these values for the total number of species potentially present. Index for assessing the potential of interspecific killing (here named body size factor) was computed through Donadio and Buskirk (2006) arcsine square root of BSC defined as the body size difference for each species pair, which is calculated through the equation $\mathrm{BSD}=$ $\left(M b_{l}-M b_{s}\right) / M b_{l}$, where $M b_{l}$ is the mass of the larger species and $M b_{s}$ the mass of the smaller one. If the result of arcsine $\sqrt{B S D}$ was between 2 and 5.4, than we could consider the pair of species as potential competitors directly influencing each other via interspecific killing (see Donadio and Buskirk 2006 for more details). For example, at locality $\mathrm{X}$ we recorded a skull of $C$. thous. In this locality the species could potentially interact with $L$. gymnocercus due to habitat preference (open grasslands) and diet overlap (Vieira and Port 2007), but not by interspecific killing because the pair $C$. thous and L. gymnocercus has arcsine $\sqrt{B S D}$ lower than two (see Donadio and Buskirk 2006). Speothos venaticus is also present at this locality. This last species is not a potential competitor with $C$. thous in any of our factors because this pair of species arcsine $\sqrt{B S D}$ is lower than 2 (see Donadio and Buskirk 2006). They do not overlap in dietary adaptation due to the fact that $C$. thous presents an omnivorous diet while $S$. venaticus is a specialized meat eater. For habitat preference, $C$. thous prefers open grassland areas (Berta 1982) and S. venaticus is primarily a forest dweller (Oliveira 2009). Thus, we have a value of 0 for interspecific killing and 0.5 for diet and 0.5 for habitat (half of the species in that location is a potential competitor due to diet and habitat preferences). We performed this calculation for every specimen, constructing a table that was then used to test competition via PLS between shape or size and the competition data matrix.

\section{Angular Comparison}

After assessing via PLS the impact of climate and competition versus skull shape, MorphoJ 1.05 (Klingenberg 2011) was used to compare the direction of PLS shape vectors extracted for climate and competition, separately. This provides a direct test to assess the impact of these factors on shaping canid communities and phenotypic changes. Such a test was not available for PLS size for which we opted to simply compare strength of correlation between the samples. If climate impacts size more strongly than competition we might expect higher correlation coefficient (=r) in PLS.

\section{Variation Partitioning}

We employed variation partitioning (Diniz-Filho and Bini 2008; Raia et al. 2010; Meloro et al. 2014a) to evaluate the singular contribution to skull shape variance of four distinct components: taxonomy (described by the categorical variable "species"), size (described by $\operatorname{lnCS}$ ), climate (described by the nineteen bioclimatic indices) and competition 
(described by the three variables of size, diet and biome overlap between the species). These factors are all considered as predictors (X) of skull shape (Y, described by the 54 shape variables, $2 n-4$ where $n$ is the number of landmarks, Rohlf and Slice 1990) into multiple multivariate regression models. We tested for the effect of each single factor in isolation and in interaction with each other using the R package vegan 2.0 (Oksanen et al. 2012). We also analyzed the contribution of different predictors into size variation. We performed variation partitioning between all the average per localities ( $\mathrm{N}=262$; using taxonomy, climate and competition as factors). These procedures were employed for the overall sample of South-American canids and nested subsets of the genera Cerdocyon and Lycalopex that got sufficient data to be considered separately. Since Lycalopex is the only genus that is not monophyletic, we also included taxonomy in its model. The other genera were not analyzed separately due to low number of localities.

\section{Comparative Methods}

Skull size and shape values together with bioclimatic and competition parameters were averaged across species in order to identify correlation patterns at macroevolutionary (above species) level.

This new dataset included eight data points only. We tested again for allometric patterns in between species as well as impact of climate and competition using Partial Least Squares. Due to species shared ancestry, we firstly produced a molecular phylogeny of our selected taxa using the $10 \mathrm{k}$ tree project database (Arnold et al. 2010, Online Resource). This database provided access to all updated molecular data of extant Canidae and generated consensus phylogenetic tree based on a baysean approach using selected taxa only. MorphoJ was employed to test for the presence of a phylogenetic signal in our shape data comparing the observed sum of procrustes distances between the eight species averaged shapes and their reconstructed ancestral node values versus the distribution of these sums obtained randomizing tips and node values (cf. Klingenberg and Gidaszewski 2010; Meloro and Jones 2012). Regressions and Partial Least Squares models were eventually repeated on independent contrasts using MorphoJ in order to re-evaluate the influence of allometry, climate and competition on macroevolutionary scale (cf. Meloro et al. 2014a, b).

\section{Results}

\section{Canids Skull Shape}

The first twenty five Relative Warps cumulatively explain $95 \%$ of total variance. Plotting the first $(30.50 \%$ of shape variance) versus the second (19.96\%) RWs evidence extensive overlap between the different canids' species, although RW1 separates genera, showing some segregation between almost all Lycalopex spp. and the others (Fig. 3). Only $S$. venaticus did not overlap with others species. RW1 describes changes in the zygomatic arch, occipital condyle, auditory bulla, muzzle and teeth. Species at the extreme negative of RW1 exhibit smaller zygomatic arch, occipital condyle and auditory bulla, more elongated and thinner muzzle, larger first molar and carnassial and smaller canine and incisors. The RW2 describes shape changes related to braincase, zygomatic arch, occipital condyle, auditory bulla, muzzle area and teeth row positioning and size. On the negative scores of RW2 specimens have larger braincase, zygomatic arch, occipital condyle and auditory bulla, shorter and thicker muzzle, small first molar and larger carnassial, canine and incisors.

MANOVA performed using the first $25 \mathrm{RWs}$ evidenced significant shape differences between species $(\mathrm{N}=262$, Pillai's trace $\left.=4.116 ; \mathrm{F}_{175}, \quad 1652=13.471 ; P \ll 0.001\right)$. When only locality average sexed individuals were analyzed ( $\mathrm{N}=206$ ), two-way MANOVA shows no significant differences between sex (Pillai's trace $=0.173$; $\left.\mathrm{F}_{25}, \quad 165=1.385 ; \quad P=0.118\right)$, but confirms significant differences between species (Pillai's trace $=4.146$; $\left.\mathrm{F}_{175, \quad 1197}=9.936 ; \quad P \ll 0.001\right)$, with no interaction between the two factors (Pillai's trace $=0.895$; $\left.\mathrm{F}_{175, \quad 1197}=1.003 ; \quad P=0.477\right)$. Pairwise comparisons using the first two RWs (50.46\% of total variance) revealed that all species differ in skull shape, expect for the pair Lycalopex culpaeus-L. griseus, L. culpaeus-L. gymnocercus and Atelocynus microtis-L. vetulus (Table 2).

\section{Skull Size}

Two-way ANOVA $(\mathrm{N}=206)$ revealed canid species to be significantly different in skull size $(\mathrm{F}=123.069, d f=7$, $P \ll 0.001)$. Males and females also differ in skull size (F $=7.946, \mathrm{t}=1, P=0.005)$ but no interaction occurs between taxonomy and sex in skull size $(\mathrm{F}=1.057$, $d f=7, P=0.393$ ). Therefore, it was possible to use in subsequent analyses the localities averages including those individuals who lacked sex information. One-way ANOVA confirmed species to be significantly different in size after averaging by geographic localities $(\mathrm{F}=194.9, d f=7$, $P \ll 0.001)$. Paired comparisons revealed that all species differ in size, except the pair A. microtis-L. culpaeus and $L$. gymnocercus-S. venaticus (Table 3; Fig. 4).

\section{Skull Allometry}

Size had a significant impact on skull shape explaining $7.84 \%$ of variance in the global skull sample $(\mathrm{N}=431, P \ll 0.0001$, 


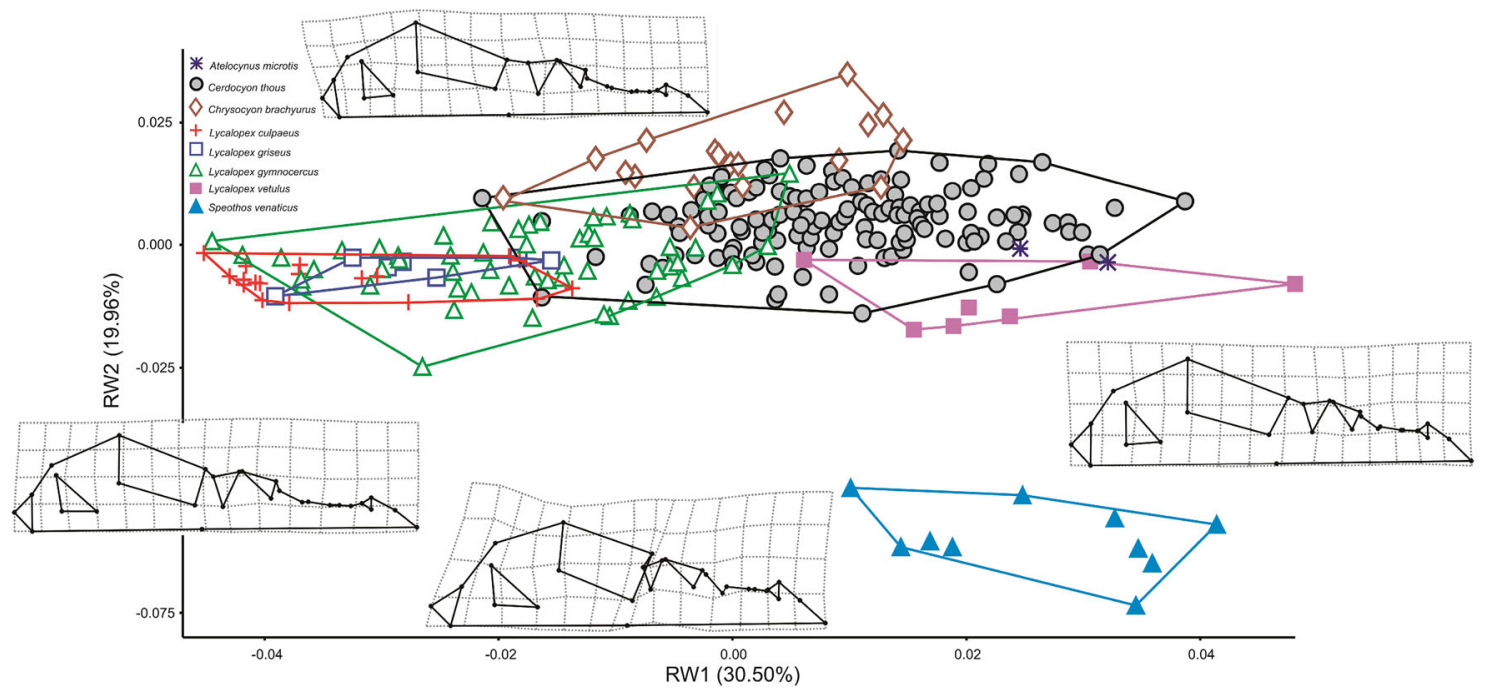

Fig. 3 Scatter plot of RW1 versus RW2. Transformation grids visualize shape deformations relative to the mean at the positive and negative extremes of Relative Warps axes. Every species is labeled

according to different color and symbol within minimum convex hull superimposed (Color figure online)

Table 2 Pairwise comparisons between South-American canid species for skull shape

\begin{tabular}{lcccccccc}
\hline & A. microtis & C. thous & Ch. brachyurus & L. culpaeus & L. griseus & L. gymnocercus & L. vetulus & S. venaticus \\
\hline A. microtis & & $\mathbf{0 . 0 0 8}$ & $\ll \mathbf{0 . 0 0 1}$ & $<\mathbf{0 . 0 0 1}$ & $\ll \mathbf{0 . 0 0 1}$ & $\ll \mathbf{0 . 0 0 1}$ & 0.275 & $\ll \mathbf{0 . 0 0 1}$ \\
C. thous & 4.924 & & $\ll \mathbf{0 . 0 0 1}$ & $\ll \mathbf{0 . 0 0 1}$ & $\ll \mathbf{0 . 0 0 1}$ & $\ll \mathbf{0 . 0 0 1}$ & $\ll \mathbf{0 . 0 0 1}$ & $\ll \mathbf{0 . 0 0 1}$ \\
Ch. brachyurus & 29.160 & 45.111 & & $\ll \mathbf{0 . 0 0 1}$ & $\ll \mathbf{0 . 0 0 1}$ & $\ll \mathbf{0 . 0 0 1}$ & $\ll \mathbf{0 . 0 0 1}$ & $\ll \mathbf{0 . 0 0 1}$ \\
L. culpaeus & 40.531 & 41.745 & 34.926 & & 0.107 & 0.142 & $\ll \mathbf{0 . 0 0 1}$ & $\ll \mathbf{0 . 0 0 1}$ \\
L. griseus & 38.199 & 150.730 & 115.400 & 2.472 & & $\ll \mathbf{0 . 0 0 1}$ & $\ll \mathbf{0 . 0 0 1}$ & $\ll \mathbf{0 . 0 0 1}$ \\
L. gymnocercus & 15.378 & 126.780 & 63.463 & 2.0208 & 14.211 & & $\ll \mathbf{0 . 0 0 1}$ & $\ll \mathbf{0 . 0 0 1}$ \\
L. vetulus & 1.6110 & 28.661 & 84.289 & 43.912 & 67.453 & 48.654 & \\
S. venaticus & 67.480 & 496.61 & 447.590 & 205.290 & 410.350 & 390.020 & 107.510 & $\ll \mathbf{0 . 0 0 1}$
\end{tabular}

Upper diagonal corresponds to $P$ values and lower diagonal corresponds to F values. Significant is highlighted

Table 3 Pairwise $t$ test between South-American canid species for skull size

\begin{tabular}{|c|c|c|c|c|c|c|c|}
\hline & A. microtis & C. thous & Ch. brachyurus & L. culpaeus & L. griseus & L. gymnocercus & S. venaticus \\
\hline C. thous & 0.002 & & & & & & \\
\hline Ch. brachyurus & $\ll \mathbf{0 . 0 0 1}$ & $\ll \mathbf{0 . 0 0 1}$ & & & & & \\
\hline L. culpaeus & 0.488 & $\ll \mathbf{0 . 0 0 1}$ & $\ll \mathbf{0 . 0 0 1}$ & & & & \\
\hline L. griseus & $\ll \mathbf{0 . 0 0 1}$ & $\ll \mathbf{0 . 0 0 1}$ & $\ll 0.001$ & $\ll 0.001$ & $\ll \mathbf{0 . 0 0 1}$ & & \\
\hline L. gymnocercus & $\ll \mathbf{0 . 0 0 1}$ & $\ll \mathbf{0 . 0 0 1}$ & $\ll \mathbf{0 . 0 0 1}$ & $\ll 0.001$ & $\ll \mathbf{0 . 0 0 1}$ & & \\
\hline S. venaticus & $\ll \mathbf{0 . 0 0 1}$ & $\ll \mathbf{0 . 0 0 1}$ & $\ll \mathbf{0 . 0 0 1}$ & $\ll 0.001$ & $\ll \mathbf{0 . 0 0 1}$ & 0.140 & \\
\hline L. vetulus & $\ll \mathbf{0 . 0 0 1}$ & $\ll \mathbf{0 . 0 0 1}$ & $\ll \mathbf{0 . 0 0 1}$ & $\ll 0.001$ & 0.043 & $\ll \mathbf{0 . 0 0 1}$ & $\ll \mathbf{0 . 0 0 1}$ \\
\hline
\end{tabular}

Significant $P$ value is highlighted

see also Online Resource) and $9.46 \%$ of variance in the locality averaged sub-sample $(\mathrm{N}=262, P \ll 0.0001$, see also Online Resource). ANCOVA models with permutation demonstrated in all cases that slope differ between species $(\mathrm{N}=431$, $\mathrm{F}=8.713, P<0.001 ; \mathrm{N}=262, \mathrm{~F}=1.872, P<0.001)$.
Allometric models using pooled regression within subgroups are also significant in all cases $(\mathrm{N}=431,3.29 \mathrm{Var} \%$, $P<0.001 ; \mathrm{N}=262,3.77 \operatorname{Var} \%, P<0.001)$.

Regression models performed independently for each taxon (Table 4) demonstrates that allometric effect impact 
Fig. 4 Box plot with standardized deviation of natural $\log$ transformed centroid size (lnCS) across the SouthAmerican canid species. Black string median, white box first interquartile, bar second interquartile

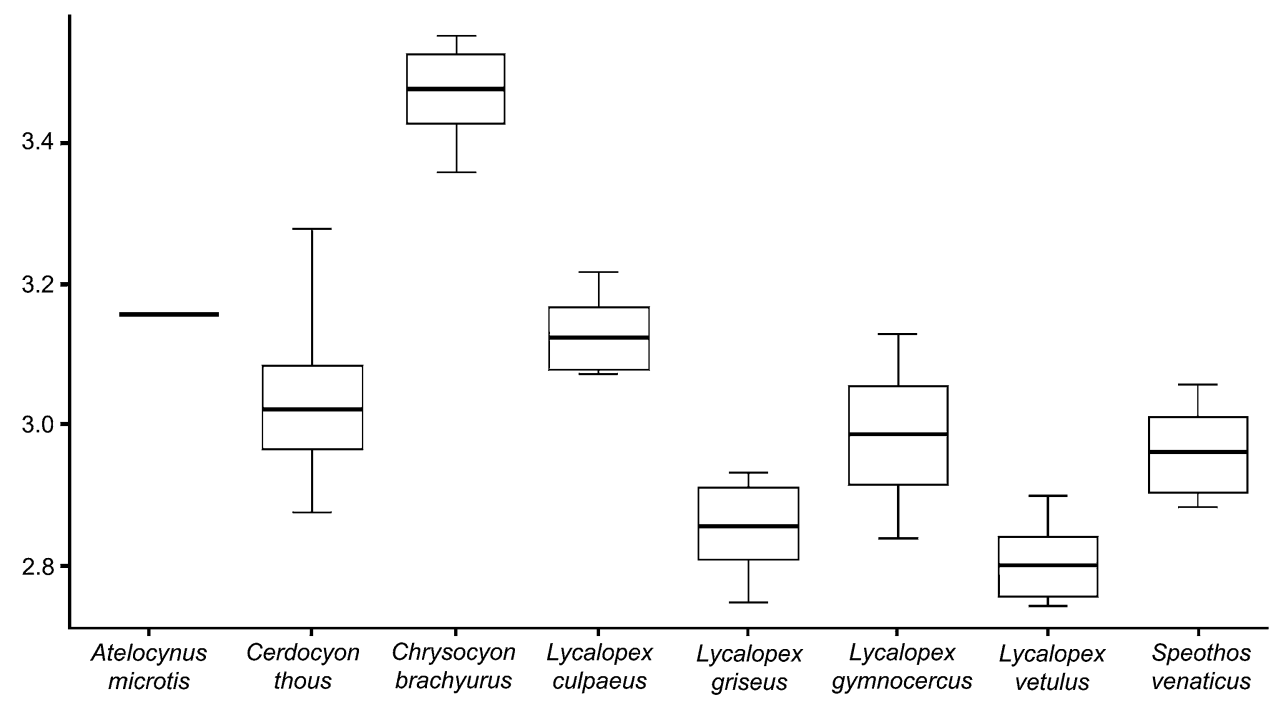

Table 4 Regressions between skull shape and lnCS in different subsamples of canid taxa

\begin{tabular}{|c|c|c|c|c|c|c|}
\hline \multirow{2}{*}{ Species } & \multicolumn{3}{|c|}{ Whole sample } & \multicolumn{3}{|c|}{ Locality averaged } \\
\hline & $\mathrm{N}$ & $\operatorname{Var} \%$ & $P$ & $\mathrm{~N}$ & $\operatorname{Var} \%$ & $P$ \\
\hline Cerdocyon thous & 226 & 3.85 & $<0.0001$ & 143 & 4.08 & $<0.0001$ \\
\hline Chrysocyon brachyurus & 25 & 9.28 & 0.0076 & 19 & 11.52 & 0.0159 \\
\hline Lycalopex culpaeus & 13 & 10.85 & 0.835 & 7 & 25.85 & 0.0731 \\
\hline Lycalopex griseus & 33 & 4.86 & 0.1003 & 19 & 7.19 & 0.1881 \\
\hline Lycalopex gymnocercus & 99 & 4.20 & $<0.0001$ & 55 & 5.69 & 0.002 \\
\hline Lycalopex vetulus & 16 & 6.68 & 0.4329 & 7 & 26.71 & 0.0865 \\
\hline Lycalopex spp. & 161 & 9.13 & $<0.0001$ & 88 & 9.02 & $<0.0001$ \\
\hline Speothos venaticus & 15 & 13.44 & 0.0346 & 10 & 20.81 & 0.0084 \\
\hline
\end{tabular}

Significance is highlighted

species differently. In the bush dog skull size explains the highest percentage of shape variance when compared to the larger Chrysocyon and Cerdocyon. Within Lycalopex allometric shape changes occurs in L. gymnocercus only while they are not statistically detectable in the other taxa (see also Online Resource). However, if all Lycalopex species are merged in the same sample, skull size explains almost $9 \%$ of shape variance in both complete and locality averaged datasets (Table 4; see also Online Resource).

\section{PLS Climate}

Two block Partial Least Squares between 19 bioclimatic variables and skull shape extracts 19 pair of vectors of which the first explains $98.33 \%$ of covariation between the blocks. Correlation between the first pair of axes is strong $(\mathrm{r}=0.720)$ and significant $(P<0.001)$. A scatter plot with Singular Warp 1 of the shape block (SW1 shape) versus SW1 of the climate variables block supports a separation among species along an environmental gradient (Fig. 5). SW1 climate is loaded negatively on Temperature
Seasonality (standard deviation $\times 100) \quad($ BIO4, $\mathrm{r}=-0.864)$ and Temperature Annual Range (BIO7 = BIO5-BIO6; $r=-0.762$ ), while strong positive correlation of SW1 climate scores occurred with Annual Mean Temperature (BIO1, $r=0.864)$, Min Temperature of Coldest Month (BIO6, $r=0.943$ ), Mean Temperature of Driest Quarter (BIO9, $r=0.794)$, Mean Temperature of Coldest Quarter (BIO11, $r=0.931)$, Annual Precipitation (BIO12, $r=0.809$ ), Precipitation of Wettest Month (BIO13, $\mathrm{r}=0.891$ ), Precipitation of Wettest Quarter (BIO16, $\mathrm{r}=0.896$ ). Therefore, SW1 climate discriminated between seasonal and arid climate (negative scores) versus warm and humid (positive scores).

Species distributed in localities with low precipitation, low mean temperatures and high seasonality exhibited skulls with elongated muzzles, smaller zygomatic arch, larger teeth, narrow auditory bulla and smaller occipital condyle (e.g. L. griseus, L. culpaeus and most of L. gymnocercus representatives). Conversely, A. microtis, $S$. venaticus, $L$. vetulus, Ch. brachyurus and most of $C$. thous representatives showed positive scores in vector SW1 


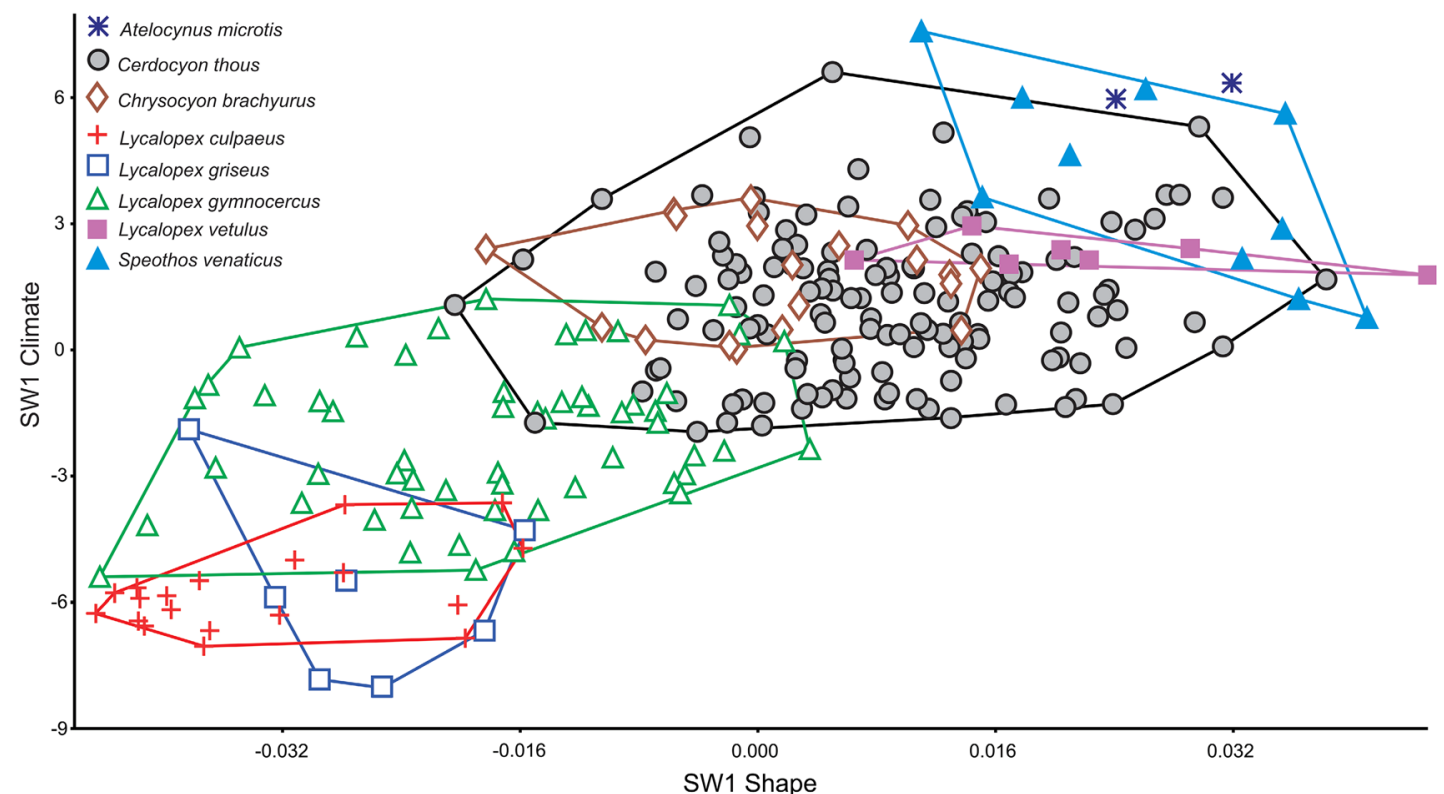

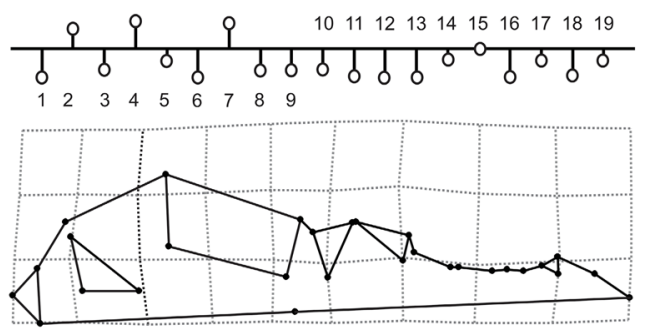

Fig. 5 Plot of the first pair of Singular Warps (axis $X$ is block shape, axis $Y$ is block climate). Below deformation grids and variables profile from the most negative to the most positive Singular Warps

climate (high precipitation and mean temperature and low seasonality) and therefore had antagonistic skull shape (Fig. 5).

The PLS of size versus climatic variables also extracted a significant pair of axes whose correlation is not particularly strong $(\mathrm{r}=0.275 ; P<0.001)$. SW climate is loaded positively with Temperature Seasonality (standard deviation $\times 100)(\mathrm{BIO} 4, \mathrm{r}=0.827)$. All Lycalopex species occur in high seasonal environments and are characterized by relatively small size (Fig. 6a).

\section{PLS Competition}

Two block Partial Least Squares between competition variables (Diet, Size and Biome) and skull shape extracts three pairs of vectors of which the first explains $70.97 \%$ of covariation between the blocks. Competition has significant impact on skull shape (PLS1, $\mathrm{r}=0.419, P \ll 0.001$ ). The scatter plot with Singular Warp 1 of the shape block versus SW1 of competition variables block shows two

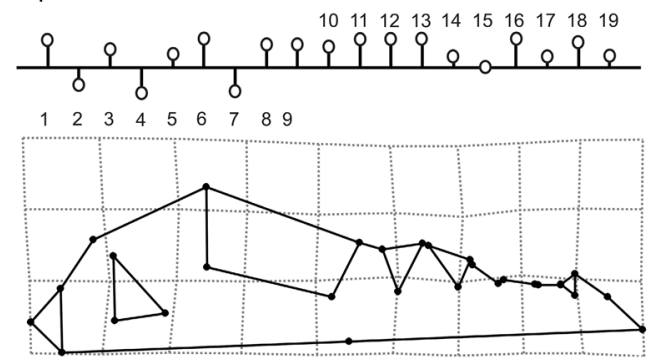

FIG

scores. Every species is labeled according to different color and symbol within minimum convex hull superimposed (Color figure online)

groups of species that differ among each other the most: the northern group, with A. microtis, most specimens of $C$. thous, Ch. brachyurus, L. vetulus and Speothos and the southern group, with mainly L. griseus and L. culpaeus. Lycalopex gymnocercus is right in the middle, overlapping in shape with both groups (Fig. 7). SW1 competition is loaded positively with all three variables (Diet $r=0.823$, Interspecific killing $\mathrm{r}=0.578$ and habitat $\mathrm{r}=0.572$ ). Adaptations in the positive end (L. griseus, L. culpaeus and L. gymnocercus) are related to skulls with a larger bulla, a small temporalis insertion area and relatively larger teeth. On negative scores we find specimens of $C$. thous, $C h$. brachyurus, $L$. vetulus and $S$. venaticus. These specimens show relatively smaller teeth, bulla and larger muzzle.

Significant association also occurs between size and competition $(\mathrm{r}=0.332 ; P<0.001)$. SW competition is loaded negatively on diet $(\mathrm{r}=-0.662)$, size $(\mathrm{r}=-0.036)$ and biome $(r=-0.748)$. Species with higher impact of competition are smaller (L. griseus) and with less impact of competition are larger (Ch. brachyurus) (Fig. 6b). 

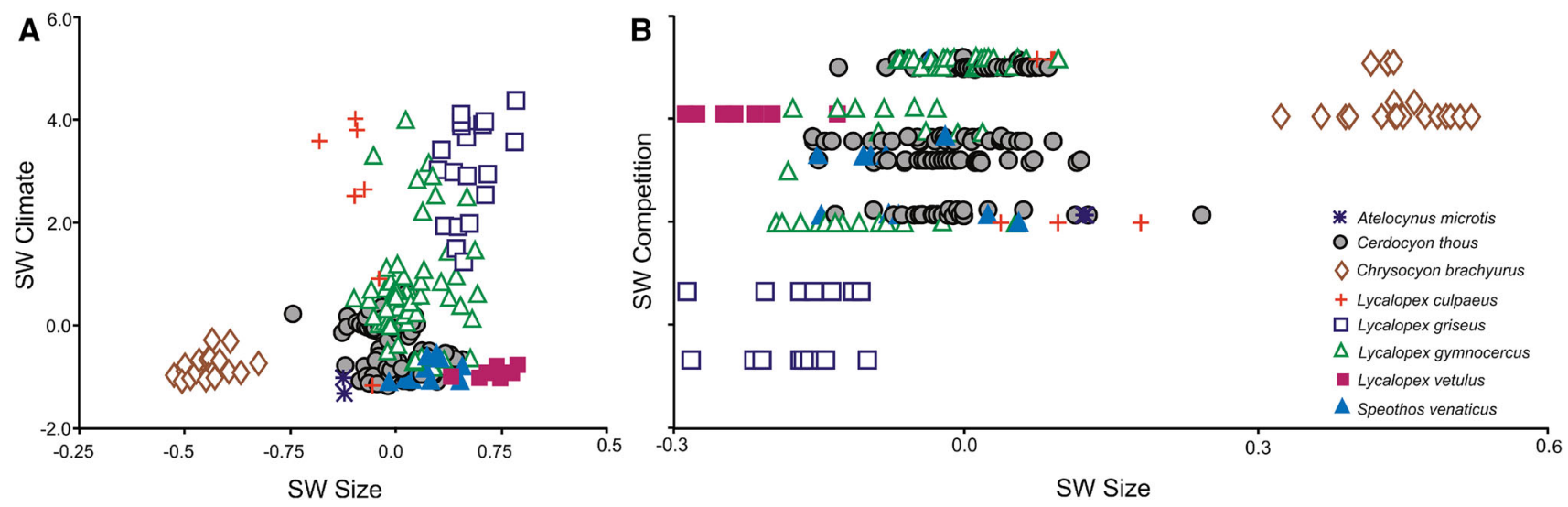

Fig. 6 Plot of the pair of Singular Warps. a Pls climate plot (axis $X$ is block size, axis $Y$ is block climate). b Plot competiton plot (axis $X$ is block size, axis $Y$ is block competition). Every species is labeled according to different color and symbol (Color figure online)

Fig. 7 Plot of the first pair of Singular Warps (axis $X$ is block shape, axis $Y$ is block competition). Below deformation grids and variables profile from the most negative to the most positive Singular Warps scores. Every species is labeled according to different color within minimum convex hull superimposed (Color figure online)
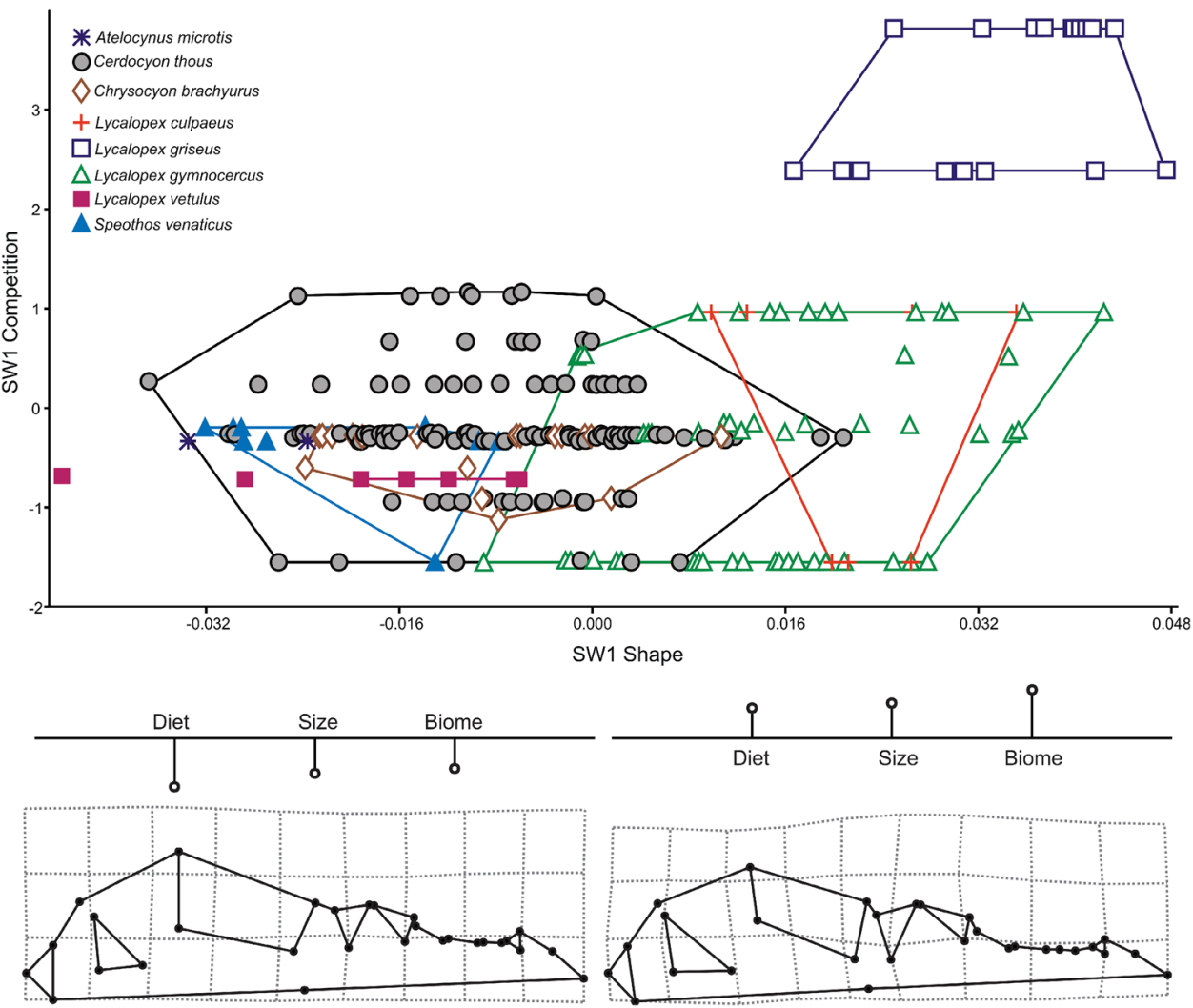

\section{Angular Comparison}

The direction of PLS shape vectors due to climate and competition are significantly distinct from $90^{\circ}$ thus supporting similarities in patterns of skull shape covariation (angle $=18.547^{\circ} ; P<0.001$ ).

Pairwise genera angular comparison for PLS climate revealed that only two pairs of species seem to exhibit similar vector directionality: Chrysocyon and Lycalopex, and Cerdocyon and Speothos (Table 5A). As to competition, only Cerdocyon and Lycalopex exhibit an angle significantly smaller than 90 degrees (Table 5B).

\section{Variation Partitioning}

In the sample of 262 skull shape averages per locality, taxonomy occurs as the most influential variable to explain interspecific shape variation (Adj $R^{2}$ Taxonomy $=0.49$ ). This pattern remains consistent if factors are considered as single "pure" components (Adj $\mathrm{R}^{2}$ Taxonomy "Pure" $=0.22$, 
Fig. 8a). Climate is the second most influential variable when considered together with other variables (Adj $\mathrm{R}^{2} \mathrm{Cli}$ mate $=0.21$ ) as well as alone (Adj $\mathrm{R}^{2}$ Climate "Pure" $=0.03$, Fig. 8a). Size and Competition have no influence on shape when considered alone (Fig. 8a). Strong interaction occurs between taxonomy and climate and taxonomy and size (Fig. 8a; Online Resource).

The same strong influence of taxonomy occurs when size is considered a predictor (Adj $\mathrm{R}^{2}$ Taxonomy $=0.84$ ). This pattern remains consistent if factors are considered as single "pure" components (Adj $\mathrm{R}^{2}$ Taxonomy "Pure" $=0.72$, Fig. 8b). After taxonomy, climate is the most influential factor (Adj $\mathrm{R}^{2}$ Climate "Pure" = 0.03), followed by competition (Adj $\mathrm{R}^{2}$ Competition "Pure" =0.01, Fig. 8b). Taxonomy interacts with competition and both together interact strongly with climate (Fig. 8b).

The analyses of nested dataset show distinct partition of variance depending on the genus. In Cerdocyon size has no significant influence on skull shape as "pure" component. The impact of climate on skull shape is present and significant (Adj $\mathrm{R}^{2}$ Climate "pure" $=0.10$ ) while competition explains very little (Adj $\mathrm{R}^{2}$ Competition "pure" $=0.01$, and see Online Resource). When Cerdocyon skull size is modelled as dependent variable, competition is more influential in isolation (Adj $\mathrm{R}^{2}$ Competition "pure" $=0.07$ ) while climate has an impact only due to the interaction with the competition (Adj $\mathrm{R}^{2}$ Climate $\times$ Competition $=0.04$; see also Online Resource).

For Lycalopex, taxonomy is the most influential factor in explaining variance for skull shape (Adj $\mathrm{R}^{2}$ Taxonomy "pure" $=0.05$ ), followed as pure component by climate (Adj $\mathrm{R}^{2}=0.04$ ), competition (Adj $\mathrm{R}^{2}=0.02$ ) and size (Adj $\mathrm{R}^{2}=0.01$ ). A similar pattern occurs when skull size is considered dependent with taxonomy as pure explaining most of the variance $\left(\operatorname{Adj} R^{2}=0.16\right)$, followed by climate

Table 5 Pairwise Angular comparisons of SW1 shape vectors of climate (A) and competition (B) between South-American canid genera

\begin{tabular}{lcccc}
\hline & Cerdocyon & Chrysocyon & Lycalopex & Speothos \\
\hline A: Climate & & & & \\
Cerdocyon & & 0.576 & 0.329 & $\mathbf{0 . 0 0 1}$ \\
Chrysocyon & 85.584 & & $<\mathbf{0 . 0 0 1}$ & 0.365 \\
Lycalopex & 82.293 & 60.375 & & 0.056 \\
Speothos & 64.420 & 82.845 & 74.994 & \\
B: Competition & & & & \\
Cerdocyon & - & 0.628 & $\mathbf{0 . 0 1 3}$ & 0.651 \\
Chrysocyon & 86.171 & - & 0.242 & 0.449 \\
Lycalopex & 70.590 & 80.763 & - & 0.314 \\
Speothos & 86.427 & 84.022 & 82.048 & -
\end{tabular}

Upper diagonal corresponds to $P$ values and lower diagonal corresponds to angles (in ${ }^{\circ}$ ). Significant is highlighted
(Adj $\left.\mathrm{R}^{2}=0.08\right)$ and competition $\left(\operatorname{Adj} \mathrm{R}^{2}=0.02\right.$; see also Online Resource).

\section{Comparative Analyses}

When using the record of averaged skull shape $(\mathrm{N}=8)$, allometry is not a significant factor anymore even if skull size appears to explain a substantial proportion of shape variance $(16.46 \% ; P=0.332)$. The Partial Least Squares confirms the impact of climatic variables on skull shape as detectable by the first significant pair of vectors $(93.27 \%$ of covariation explained, $\mathrm{r}=0.957, P=0.0083$ ). Association between skull shape and competition is not statistically detectable with PLS (SW1, $r=0.8655$, $P=0.1954)$. The test for phylogenetic signal shows that it does not occur in both skull shape (Tree length $=0.0067$, $P=0.2063$ ) and size (Tree length $=0.218, P=0.4438$ ) making it unnecessary the use of comparative methods.

\section{Discussion}

Our findings show South-American canids are different in skull shape, with peculiar characters occurring especially in S. venaticus: large zygomatic arch, big upper carnassial, canine and incisors and short and thick muzzle are all wellestablished attributes related to its hypercarnivorous diet (Valkenburgh 1991; Kleiman 1972). The tropical hoaryfox (L. vetulus) also shows unique skull shape in comparison to other Lycalopex southern species. Features such as large auditory bulla and short and thick muzzle make the hoary-fox more similar in skull shape to Cerdocyon and Atelocynus than to members of its own genus (Fig. 2). In comparison to the southern South-American Lycalopex, the hoary-fox is endemic of central Brazil and termites are a large percentage of its diet (Dalponte 2009). The other Lycalopex foxes are omnivorous, opportunistic and restricted to colder environments, so this might explain the unusual grouping in cranial shape of L. vetulus with other genera (Sillero-Zubiri et al. 2004; Johnson and Franklin 2011).

Skull size also varies considerably among species with Ch. brachyurus showing the largest skull. Size differences also occur among members of Lycalopex genus confirming and expanding previous observations by Wayne et al. (1989): size differentiation can be interpreted as a mechanism of niche partitioning that eventually allowed these taxa to fulfil different ecological requirements. As such, the role of interspecific allometry in the overall sample is apparent with size explaining almost $10 \%$ of variance in skull shape (generally comparable to that from previous studies, Figueirido et al. 2011, 2013 on all Carnivora and Meloro et al. 2015b on canids only). The ANCOVA model 

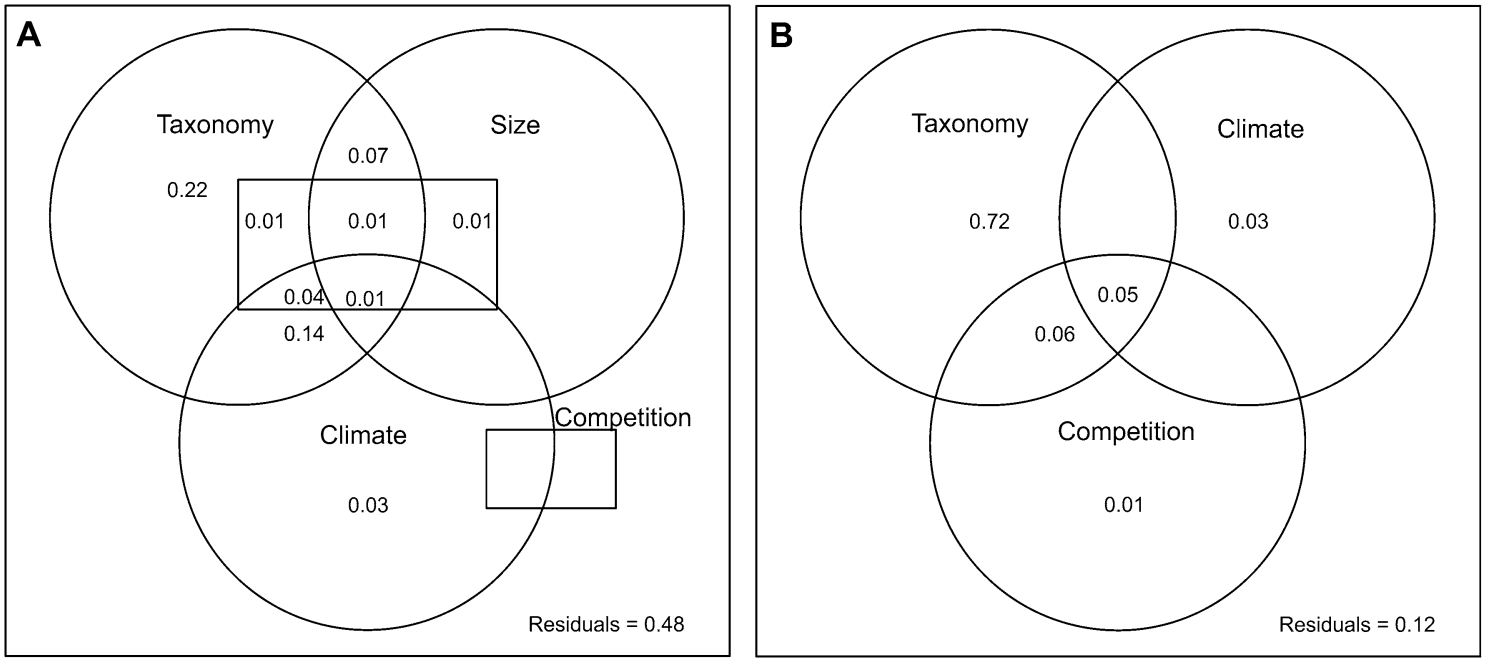

Fig. 8 Schematic depiction of the factors analyzed in partition variation meant to illustrate both their individual contribution to shape (a) or size (b) variance and their interaction components. Values $<0$ not shown

suggests that allometric shape variation differs between taxa to the extent that more specialised morphologies show greater percentage of variance explained by size rather than generalists one (Table 4). Indeed, the hypercarnivorous bush dog (S. venaticus) exhibits a strong allometric component when compared to the other taxa in relation to its biomechanically demanding predatory behaviour (Slater et al. 2009). We also note that allometry is not significant for many Lycalopex species except $L$. gymnocerus. This possibly might be the result of a broader taxonomic differentiation that occurred in the whole genus in relation to size but not shape characteristics (see Tables 2, 3). Also localized character displacement in certain members of this genus might have favoured size changes not accompanied by dramatic skull shape changes. Prevosti et al. (2013) supports allometry to occur in a 3D skull shape sample of L. griseus and L. gymnocercus thus corroborating our general result based on the Lycalopex as a coherent taxonomic group.

Clearly allometry is a factor in shape differentiation of South American canids, however the PLS and variation partition analyses support a stronger influence of abiotic factors on skull morphology.

Climate seems to represent a stronger factor than competition in explaining skull shape variation. PLS highlights this and also provides the mechanism to visualize shape and size changes related to these factors. Seasonal environments, such as southern South-America, are occupied by non-specialist canid phenotypes, due to Lycalopex dominance. Opposite to that, inside the Amazon we have the co-presence of three distinct morphotypes: Speothos, Atelocynus and the generalist Cerdocyon. The peculiar interaction between these genera occurs only in this biome.
Compared to other South-American ecoregions where $S$. venaticus is rarely encountered, its species abundance in the Amazon is higher (Jorge et al. 2013). Meanwhile, A. microtis is mainly an Amazonian species whose ecological niche relates strongly with wet environments (e.g. main food source is generally fish, Berta 1986; Sillero-Zubiri et al. 2004). From a macroevolutionary point of view this supports the Amazon as a unique ecosystem hosting an ecologically and morphologically diverse canid community with predominance of carnivorous morphotypes (skulls characterised by large zygomatic arch and short rostrum, Fig. 5). We note still all over South America a general pattern of co-presence involving rather three species in different climatic conditions: far from the equator, the coexistence of fox-like phenotypes increases, suggesting that carnivorous phenotypes went extinct and never replaced; in the savannah-Cerrado environments we record skulls of Chrysocyon, Cerdocyon and Lycalopex (depending on the latitude co-occurrence is with $L$. gymnocercus or $L$. vetulus, Fig. 5). Jácomo et al. (2004) report low degree of ecological overlap between Chrysocyon, Cerdocyon and L. vetulus in Cerrado due to differences in feeding habits and activity patterns. The bush dog is also expected to be part of this guild although no data about its diet in co-existence with the other dogs are available. Zuercher et al. (2005) report high consumption of agouti and paca by Speothos in Atlantic Forest of eastern Paraguay. If diet of Speothos is consistent across the continent we might expect some possible overlap with the maned wolf and the crab-eating fox, however no report of bush dog killing by larger canids occurs in the literature (Oliveira and Pereira 2014).

The size pattern related to climate is not as strong as with shape and we note generally smaller species in the 
southern part of South America co-existing together (Fig. 6a). The lack of large carnivorous morphotypes is a relatively recent event in the history of southern SouthAmerican canids thus explaining it. Fossil record supports this, since Theriodictis and Protocyon genera (large hypercarnivores) were recorded in southern South America and went extinct very recently at the end of the Pleistocene (Prevosti et al. 2009b).

The co-presence of three distinct morphotypes in size and shape definitely occurs along an environmental gradient and can be better interpreted after looking at PLS of skull morphology versus competition (Fig. 7). All Lycalopex foxes exhibit similar shape morphology and high scores being generally the smallest in the canid guild and showing strong overlap with each other across their range. This co-existence seems interestingly favoured by size differences more than shape (Figs. 3, 4) confirming earlier investigation (Fuentes and Jaksic 1979).

The parallelism observed in the PLS vectors suggests that co-variation between shape with climate and competition gradient are two sides of the same coin. Indeed, canid assemblage rules are definitely controlled by environment and South-American species are no exception (Johnson et al. 1996). The largest canid assemblage ever studied is from central Africa with three species of jackals co-occurring together plus hypercarnivore Lycaon and the termite specialist Otocyon.

Theoretically the Cerrado (a savannah-like vegetation) could support a similar combination of species and we note again similar niche partitioning with two foxes (Cerdocyon and Lycalopex) that overlap slightly in skull shape but not in size and feeding habits, then the small hypercarnivore bush dog and the large maned wolf.

Variation partitioning provides strong support for abiotic forces as responsible of interspecific morphological differences in South-American canids as a whole but also in the nested dataset of Cerdocyon and Lycalopex (Fig. 8; Online Resource). Climate consistently explains $3 \%$ of both size and shape variance in isolation, while competition only $1 \%$ for size and none for shape.

In Cerdocyon the impact of climate on cranial shape is even stronger $(10 \%)$ although it becomes non-significant to explain skull size variation. It can be argued that size changes in Cerdocyon are strongly influenced by co-occurrence with larger taxa that might suppress its spectrum of ecological adaptations via direct killing (Oliveira and Pereira 2014). For Lycalopex climate also appears to have stronger influence on skull size $(8 \%)$ and shape (4\%) than competition.

Overall, these results are a bit counterintuitive considering the rapid adaptive invasion of canids in South America (Perini et al. 2010). This explains the lack of phylogenetic signal encountered in macroevolutionary analyses as well as lack of allometry, but still significant influence of climate. Benton (2009) suggests that competition might regulate animal communities on short time scale, while abiotic forces dominate on big temporal scale. We argue that SouthAmerican canids show a mix of both phenomena since prehistoric diversity was higher, when competition could have been more relevant than now (Wang et al. 2008). By adapting flexible ecological feeding niches (with the possible exception of hypercarnivorous Speothos) South-American canids might have escaped constrains imposed by competition evolving a flexible morphology.

Acknowledgments Our thanks to colleagues Jonas Sponchiado and Geruza L. Melo of the Laboratório de Ecologia e Biogeografia of the Federal University of Santa Maria for their help in data collection. We are also grateful to curators and staff of the Museu de Ciências Naturais da Fundação Zoobotânica do Rio Grande do Sul (MCNFZB) (M.M. de A. Jardim), Museu de Ciências e Tecnologia da PUCRS (MCP) (C.S. Fontana), Museu Nacional (MN) (J.A. de Oliveira and S.M. Vaz), Museu Paraense Emílio Goeldi (MPEG) (S.M. Aguiar and J.S. Silva Jr.), Museu de História Natural Capão da Imbuia (MHNCI) (V. Abilhoa and S.C. Pereira), Coleção Científica do Laboratório de Mamíferos Aquáticos da UFSC (UFSC) (M.E. Graipel), Museu Nacional Uruguaio de Historia Natural (MNHN) (E.M. Gonzalez), Museo Argentino de Ciencias Naturales "Bernardino Rivadavia" (MACN) (D.A. Flores and S. Lucero) and Museu de Zoologia da Universidade de São Paulo (MZUSP) (M. De Vivo and J.G. Barros) for the authorization and support to specimens access. Authors Jamile de Moura Bubadué and Renan dos Santos Carvalho were supported by Coordenação de Aperfeiçoamento de Pessoal de Nível Superior with a scholarship. Nilton Cáceres participated to this study as Conselho Nacional de Desenvolvimento Científico e Tecnológico research fellow in Brazil. Carlo Meloro was supported by British Research Council under the program Research Links (Grant No. 127432108). We are also grateful to editor Benedikt Hallgrimsson and two anonymous reviewers for their helpful comments.

\section{Compliance with Ethical Standards}

Conflict of Interest The authors declare that they have no conflict of interest.

Open Access This article is distributed under the terms of the Creative Commons Attribution 4.0 International License (http://crea tivecommons.org/licenses/by/4.0/), which permits unrestricted use, distribution, and reproduction in any medium, provided you give appropriate credit to the original author(s) and the source, provide a link to the Creative Commons license, and indicate if changes were made.

\section{References}

Adams, D. C., \& Otarola-Castillo, E. (2013). Geomorph: An R package for the collection and analysis of geometric morphometric shape data. Methods in Ecology and Evolution, 4, 393-399.

Adams, D. C., Rohlf, F. J., \& Slice, D. E. (2004). Geometric morphometrics: Ten years of progress following the 'revolution'. Italian Journal of Zoology, 71, 5-16.

Adams, D. C., Rohlf, F. J., \& Slice, D. E. (2013). A field comes of age: Geometric morphometrics in the 21 st century. Hystrix, the Italian Journal of Mammalogy, 24, 7-14. 
Arnold, C., Matthews, L. J., \& Nunn, C. L. (2010). The 10kTrees website: A new online resource for primate phylogeny. Evolutionary Anthropology, 19, 114-118.

Benton, M. J. (2009). The red queen and the court jester: Species diversity and the role of biotic and abiotic factors through time. Science, 323, 728-732.

Berta, A. (1982). Cerdocyon thous. Mammalian Species, 186, 1-4.

Berta, A. (1986). Atelocynus microtis. Mammalian Species, 256, 1-3.

Berta, A. (1987). Origin, diversification, and zoogeography of the South American Canidae. Fieldiana Zoology, 39, 455-471.

Cáceres, N., Meloro, C., Carotenuto, F., Passaro, F., Sponchiado, J., Melo, G. L., \& Raia, P. (2014). Ecogeographical variation in skull shape of capuchin monkeys. Journal of Biogeography, 41, 501-512.

Cardini, A., \& Elton, S. (2008). Variation in guenon skulls II: Sexual dimorphism. Journal of Human Evolution, 54, 638-647.

Cardini, A., Jansson, A.-U., \& Elton, S. (2007). Ecomorphology of vervet monkeys: A geometric morphometric approach to the study of clinal variation. Journal of Biogeography, 34, $1663-1678$.

Cardini, A., \& Tongiorgi, P. (2003). Yellow-bellied marmots 'in the shape space': Sexual dimorphism, growth and allometry of the mandible. Zoomorphology, 122, 11-23.

Cavallini, P. (1995). Variation in the body size of the red fox. Annales Zoologici Fennici, 32, 421-427.

Churcher, C. S. (1960). Cranial variation in the north American red fox. Journal of Mammalogy, 41, 349-360.

Dalponte, J. C. (2009). Lycalopex vetulus (Carnivora: Canidae). Mammalian Species, 847, 1-7.

Davis, S. (1977). Size variation of the fox, Vulpes vulpes in the palaearctic region today, and in Israel during the late Quaternary. Journal of Zoology, 182, 343-351.

Dayan, T., \& Simberloff, D. (2005). Ecological and community-wide character displacement: The next generation. Ecology Letters, 8, 875-894.

Dayan, T., Simberloff, D., Tchernov, E., \& Yom-Tov, Y. (1992). Canine carnassials: Character displacement in the wolves, jackals and foxes of Israel. Biological Journal of the Linnean Society, 45, 315-331.

Dayan, T., Tchernov, E., Yom-Tov, Y., \& Simberloff, D. (1989). Ecological character displacement in Saharo-Arabian Vulpes: Outfoxing Bergmann's rule. Oikos, 55, 263-272.

Di Bitetti, M. S., Di Blanco, Y. E., Pereira, J. A., Paviolo, A., \& Pírez, I. J. (2009). Time partitioning favors the coexistence of sympatric crab-eating foxes (Cerdocyon thous) and pampas foxes (Lycalopex gymnocercus). Journal of Mammalogy, 90, 479-490.

Diniz-Filho, J. A. F., \& Bini, L. M. (2008). Macroecology, global change and the shadow of forgotten ancestors. Global Ecology and Biogeography, 17, 11-17.

Donadio, E., \& Buskirk, S. W. (2006). Diet, morphology, and interspecific killing in carnivora. The American Naturalist, 167, 524-536.

Figueirido, B., MacLeod, N., Krieger, J., De Renzi, M., Pérez-Claros, J. A., \& Palmqvist, P. (2011). Constraint and adaptation in the evolution of carnivoran skull shape. Paleobiology, 37, 490-518.

Figueirido, B., Tseng, Z. J., \& Martín-Serra, A. (2013). Skull shape evolution in durophagous carnivorans. Evolution, 67, 1975-1993.

Fuentes, E. R., \& Jaksic, F. M. (1979). Latitudinal size variation of Chilean foxes: Test of alternative hypotheses. Ecology, 60, 43-47.

Goswami, A. (2010). Introduction to carnivoran evolution. In A. Goswami \& A. Friscia (Eds.), Carnivoran evolution: New views on phylogeny, form, and function (pp. 1-24). Cambridge: Cambridge University Press.
Hijmans, R. J., Cameron, S. E., Parra, J. L., Jones, P. G., \& Jarvis, A. (2005). Very high resolution interpolated climate surfaces for global land areas. International Journal of Climatology, 25, 1965-1978.

Jácomo, A. T. A., Silveira, L., \& Diniz-Filho, J. A. F. (2004). Niche separation between the maned wolf (Chrysocyon brachyurus), the crab-eating fox (Dusicyon thous) and the hoary fox (Dusicyon vetulus) in central Brazil. Journal of Zoology, 262, 99-106.

Johnson, W. E., \& Franklin, W. L. (2011). Spatial resource partitioning by sympatric grey fox (Dusicyon griseus) and culpeo fox (Dusicyon culpaeus) in southern Chile. Canadian Journal of Zoology, 72, 1788-1793.

Johnson, W. E., Fuller, T. K., \& Franklin, W. L. (1996). Sympatry in canids: A review and assessment. In J. L. Gittleman (Ed.), Carnivore behaviour, ecology, and evolution (Vol. 2, pp. 189-218). New York: Cornell University Press.

Jorge, R. P. S., Beisiegel, B. M., Lima, E. S., Jorge, M. L. S. P., LeitePitman, M. R. P., \& Paula, R. C. (2013). Avaliação do estado de conservação do cachorro-vinagre Speothos venaticus (Lund 1842) no Brasil. Biodiversidade Brasileira, 3, 179-190.

Kleiman, D. (1972). Social behavior of the maned wolf (Chrysocyon brachyurus) and bush dog (Speothos venaticus): A study in contrast. Journal of Mammalogy, 53, 791-806.

Klingenberg, C. P. (1996). Multivariate allometry. In L. F. Marcus, et al. (Eds.), Advances in morphometrics. Volume 284 of the series NATO ASI series (pp. 23-49). New York: Plenum Press.

Klingenberg, C. P. (2011). MorphoJ: An integrated software package for geometric morphometrics. Molecular Ecology Resources, 11, 353-357.

Klingenberg, C. P., \& Gidaszewski, N. A. (2010). Testing and quantifying phylogenetic signals and homoplasy in morphometric data. Systematic biology, 59, 245-261.

Machado, F. D. A., \& Hingst-Zaher, E. (2009). Investigating South American biogeographic history using patterns of skull shape variation on Cerdocyon thous (Mammalia: Canidae). Biological Journal of the Linnean Society, 98, 77-84.

Martinez, P. A., Marti, D. A., Molina, W. F., \& Bidau, C. J. (2013). Bergmann's rule across the equator: A case study in Cerdocyon thous (Canidae). Journal of Animal Ecology, 82, 997-1008.

Meiri, S., Simberloff, D., \& Dayan, T. (2011). Community-wide character displacement in the presence of clines: A test of Holarctic weasel guilds. Journal of Animal Ecology, 80, 824-834.

Meiri, S., Yom-Tov, Y., \& Geffen, E. (2007). What determines conformity to Bergmann's rule? Global Ecology and Biogeography, 16, 788-794.

Meloro, C. (2011). Feeding habits of Plio-Pleistocene large carnivores as revealed by their mandibular geometry. Journal of Vertebrate Paleontology, 31, 428-446.

Meloro, C., Cáceres, N., Carotenuto, F., Passaro, F., Sponchiado, J., Melo, G. L., \& Raia, P. (2014a). Ecogeographical variation in skull morphometry of howler monkeys (Primates: Atelidae). Zoologischer Anzeiger - A Journal of Comparative Zoology, 253, 345-359.

Meloro, C., Cáceres, N., Carotenuto, F., Sponchiado, J., Melo, G. L., Passaro, F., \& Raia, P. (2014b). In and out the Amazonia: Evolutionary ecomorphology in howler and capuchin monkeys. Evolutionary Biology, 41, 38-51.

Meloro, C., Clauss, M., \& Raia, P. (2015a). Ecomorphology of Carnivora challenges convergent evolution. Organisms, Diversity and Evolution. doi:10.1007/s13127-015-0227-5.

Meloro, C., Hudson, A., \& Rook, L. (2015b). Feeding habits of extant and fossil canids as determined by their skull geometry. Journal of Zoology, 295, 178-188.

Meloro, C., \& Jones, M. E. H. (2012). Tooth and cranial disparity in the fossil relatives of Sphenodon (Rhynchocephalia) dispute the 
persistent 'living fossil' label. Journal of Evolutionary Biology, $25,2194-2209$.

Meloro, C., \& O'Higgins, P. (2011). Ecological adaptations of mandibular form in fissiped Carnivora. Journal of Mammalian Evolution, 18, 185-200.

Meloro, C., \& Raia, P. (2010). Cats and dogs down the tree: The tempo and mode of evolution in the lower carnassial of fossil and living carnivora. Evolutionary Biology, 37, 177-186.

Meloro, C., Raia, P., Piras, P., Barbera, C., \& O'Higgins, P. (2008). The shape of the mandibular corpus in large fissiped carnivores: Allometry, function and phylogeny. Zoological Journal of the Linnean Society, 154, 832-845.

Oksanen, J., Kindt, R., Legendre, P. \& O'Hara, R. B. (2012). Vegan: Community ecology package. $\mathrm{R}$ package version 2.0-5. http:// cran.rproject.org/web/packages/vegan/index.html. Accessed 24 Jan 2015 .

Oliveira, T. G. (2009). Distribution, habitat utilization and conservation of the vulnerable bush dog Speothos venaticus in northern Brazil. Oryx, 43, 247-253.

Oliveira, T. G., \& Pereira, J. A. (2014). Intraguild predation and interspecific killing as structuring forces of carnivoran communities in South America. Journal of Mammalian Evolution, 21, 427-436.

Palomares, F., \& Caro, T. M. (1999). Interspecific killing among mammalian carnivores. The American Naturalist, 153, 492-508.

Perini, F. A., Russo, C. A. M., \& Schrago, C. G. (2010). The evolution of South American endemic canids: A history of rapid diversification and morphological parallelism. Journal of Evolutionary Biology, 23, 311-322.

Prevosti, F. J. (2010). Phylogeny of the large extinct South American canids (Mammalia, Carnivora, Canidae) using a "total evidence" approach. Cladistics, 26, 456-481.

Prevosti, F. J., Segura, V., Cassini, G., \& Martin, G. M. (2013). Revision of the systematic status of patagonian and pampean gray foxes (Canidae: Lycalopex griseus and L. gymnocercus) using 3D geometric morphometrics. Mastozoología Neotropical, 20, 289-300.

Prevosti, F. J., Tonni, E. P., \& Bidegain, J. C. (2009a). Stratigraphic range of the large canids (Carnivora, Canidae) in South America, and its relevance to quaternary biostratigraphy. Quaternary International, 210, 76-81.

Prevosti, F. J., Ubilla, M., \& Perea, D. (2009b). Large extinct canids from the Pleistocene of Uruguay: Systematic, biogeographic and paleoecological remarks. Historical Biology, 21, 79-89.

Prevosti, F. J., Zurita, A. E., \& Carlini, A. A. (2005). Biostratigraphy, systematics, and paleoecology of Protocyon Giebel, 1855 (Carnivora, Canidae) in South America. Journal of South American Earth Sciences, 20, 5-12.

R Development Core Team. (2013). R: A language and environment for statistical computing. Vienna: R Foundation for Statistical Computing.

Raia, P., Carotenuto, F., Meloro, C., Piras, P., \& Pushkina, D. (2010). The shape of contention: Adaptation, history and contingency in ungulate mandibles. Evolution, 64, 1489-1503.

Rohlf, F. J. (2000). On the use of shape spaces to compare morphometric methods. Hystrix, Italian Journal of Mammology, $11,9-25$.
Rohlf, F. J. (2015). The tps series of software. Hystrix, the Italian Journal of Mammalogy. doi:10.4404/hystrix-26.1-11264.

Rohlf, F. J., \& Corti, M. (2000). Use of two-block partial least squares to study covariation in shape. Systematic Biology, 49, 740-753.

Rohlf, F. J., \& Slice, D. E. (1990). Extensions of the Procrustes method for the optimal superimposition of landmarks. Systematic Zoology, 39, 40-59.

Rosenzweig, M. L. (1995). Species diversity in space and time. Cambridge: Cambridge University Press.

Schutz, H., Polly, P. D., Krieger, J. D., \& Guralnick, R. P. (2009). Differential sexual dimorphism: Size and shape in the cranium and pelvis of grey foxes (Urocyon). Biological Journal of the Linnean Society, 96, 339-353.

Segura, V. (2013). Skull ontogeny of Lycalopex culpaeus (Carnivora: Canidae): Description of cranial traits and craniofacial sutures. Mammalia, 77, 205-214.

Segura, V., \& Prevosti, F. (2012). A quantitative approach to the cranial ontogeny of Lycalopex culpaeus (Carnivora: Canidae). Zoomorphology, 131, 79-92.

Sillero-Zubiri, C., Hoffmann, M., \& Macdonald, D. (2004). Canids: Foxes, wolves, jackals and dogs. Gland and Cambridge: IUCN.

Slater, G., Dumont, E. R., \& Van Valkenburgh, B. (2009). Implications of predatory specialization for cranial form and function in canids. Journal of Zoology, 278, 181-188.

Szuma, E. (2008). Geographic variation of tooth and skull sizes in the arctic fox Vulpes (Alopex) lagopus. Annales Zoologici Fennici, 43, 185-199.

Valkenburgh, B. V. (1991). Iterative evolution of hypercarnivory in canids (Mammalia: Carnivora): Evolutionary interactions among sympatric predators. Paleobiology, 17, 340-362.

Vieira, E. M., \& Port, D. (2007). Niche overlap and resource partitioning between two sympatric fox species in southern Brazil. Journal of Zoology, 272, 57-63.

Vrba, E. S. (1993). Turnover-pulses, the red queen and related topics. American Journal of Science, 293, 418-452.

Wang, X., Tedford, R. H., \& Antón, M. (2008). Dogs: Their fossil relatives and evolutionary history. New York: Columbia University Press.

Wayne, R. K., Benveniste, R. E., Janczewski, D. N., \& O'Brien, S. J. (1989). Molecular and biochemical evolution of the carnivora. In J. L. Gittleman (Ed.), Carnivore behavior, ecology, and evolution (Vol. 1, pp. 465-494). Berlin: Springer.

Yom-Tov, Y., \& Geffen, E. (2006). Geographic variation in body size: The effects of ambient temperature and precipitation. Oecologia, 148, 213-218.

Yom-Tov, Y., Yom-Tov, S., Barreiro, J., \& Blanco, J. C. (2007). Body size of the red fox Vulpes vulpes in Spain: The effect of agriculture. Biological Journal of the Linnean Society, 90, 729-734.

Zelditch, M. L., Swiderski, D. L., Sheets, H. D., \& Fink, W. L. (2004). Geometric morphometrics for biologists. A primer: Elsevier.

Zuercher, G. L., Gipson, P. S., \& Carrillo, O. (2005). Diet and habitat associations of bush dogs Speothos venaticus in the Interior Atlantic Forest of eastern Paraguay. Oryx, 39, 86-89. 